\section{Association of the Sweetpotato Whitefly with a Silverleaf Disorder of Squash}

\author{
David J. Schuster', James B. Kring ${ }^{2}$, and James F. Price ${ }^{3}$ \\ University of Florida, IFAS, Gulf Coast Research and Education Center, \\ Bradenton, FL 34203
}

\section{Additional index words. Bemisia tabaci, Cucurbita pepo}

Abstract. The sweetpotato whitefly, Bemisia tabaci (Gennadius), was associated with symptoms of a silverleaf disorder of acorn squash (Cucurbita pepo L. cvs. Table King Bush and Table Ace) in cage studies in the greenhouse. Symptoms appeared on uninfested leaves that developed after plants were infested with the whitefly. When the infested lower leaves were removed and the young leaves protected from infestation with insecticides, new growth was asymptomatic or nearly so and symptomatic leaves remained symptomatic. Symptom expression was related more to nymphal density than to adult density since the relationship between log nymph density and symptoms was linear when adult densities were equal.
A silverleaf disorder of squash is described that is different from the genetic leaf silvering of certain squashes and similar to, if not identical to, the leaf silvering reported in Israel in 1963 (Burger et al., 1983). Although the disorder apparently occurred sporadically in south Florida before 1987, substantial economic losses were not observed until an outbreak of the disorder occurred during the 1987-88 vegetable season (Maynard and Cantliffe, 1989). An outbreak of the sweetpotato whitefly, Bemisia tabaci (Gennadius), also began in Florida in the same season (Schuster and Price, 1987).

Symptoms of the disorder appear on young foliage, first as a blanching of veins nearest to the petiole attachment, and proceed until all veins are involved. The interveinal areas subsequently become increasingly silvered face is affected. Lower leaf surfaces do not exhibit symptoms. Petioles and stems may appear white. Fruit of yellow-fruited squashes appear pale or even white while fruit of greenfruited squashes appear lighter green or streaked longitudinally.

Paris et al. (1987) associated the disorder Agricultural Experiment Station Journal Series no. R-00549. Commercial products are mentioned in this publication solely for the purpose of providing specific information. Mention of a product does not constitute a guarantee or warranty of the products by the Agricultural Experiment Station or an endorsement over products not mentioned. This publication also reports research involving pesticides. It does not contain recommendations for their use, nor does it imply that the uses discussed here have been registered. All uses of pesticides must be registered by appropriate state and federal agencies before they can be recommended. The cost of publishing this paper was defrayed in part by the payment of page charges. Under postal regulations, this paper therefore must be hereby marked advertisement solely [o indicate this fact.

${ }^{1}$ Professor.

${ }^{2}$ Adjunct Professor.

${ }^{3}$ Associate Professor. in appearance until the entire upper leaf sur-

Received for publication 15 Mar. 1990. Florida in Israel with drought stress; however, in their trials, silvering was not prevented even by full irrigation. They suggested that other unknown factors were also involved and believed these factors to be environmental in nature. In Florida, some observations suggested a possible link between environmental factors, such as air pollution, with the disorder (Simons et al., 1988); however, in cage studies in the greenhouse, symptoms of the disorder were always associated with the sweetpotato whitefly (Bharathan et al., 1990; Hoelmer et al., 1990; Yokomi et al., 1990). Symptoms could not be induced when only adults were present but were readily induced when only nymphs were present (Yokomi et al., 1990). Symptoms appeared on uninfested new foliage, produced after the introduction of either adults (Bharathan et al., 1990) or nymphs (Hoelmer et al., 1990; Yokomi et al., 1990). When the whitefly in- festation was removed either with insecticides or by removing infested leaves, symptomatic leaves remained symptomatic but new foliage was asymptomatic (Hoelmer et al., 1990; Yokomi et al., 1990).

The purpose of the present study was to evaluate the relationship between the sweetpotato whitefly, particularly nymphal presence and density, and the expression of silverleaf symptoms in a green-fruited acorn squash.

Two experiments were conducted in a greenhouse at the Gulf Coast Research and Education Center, Bradenton, Fla., in $61 \times$ $61 \times 61-\mathrm{cm}$ cages covered with a fine mesh organdy cloth. Test plants were seeded into pots and maintained within the cages throughout the duration of the studies. Plants were watered as needed and fertilized, about once a week following plant emergenee, with a $500-\mathrm{ppm}\left(\mathrm{N} / \mathrm{P}_{2} \mathrm{O}_{5} / \mathrm{K}_{2} \mathrm{O}\right)$ solution of water soluble 20N-20P-20K fertilizer (Nutri-Leaf, Miller Chemical and Fertilizer, Hanover, Pa.).

In the first experiment, 'Table King Bush' acorn squash was seeded on 25 Oct. 1988 in three $15-\mathrm{cm}$-diameter $(1350 \mathrm{ml})$ pots in each of nine cages. On 15 Nov. when plants had one to three true leaves, they were thinned to one plant per pot. Six cages each were infested with 21 whitefly adults collected in the field from squash plants exhibiting silverleaf symptoms. On 1 Dec., three cages were fumigated with sulfotepp (Plantfume 103). The following day we excised the bottom three leaflets that were present on 15 Nov. from the plants in the fumigated cages and counted eggs, crawlers, sessile nymphs, and pupae of the sweetpotato whitefly. Plants in these cages were then treated with aldicarb (Temik). Thus, the plants in three cages were uninfested, those in three others were continuously infested, and those in the remaining three were infested for only the first half of the experiment. On 9 to 12 Jan., every leaf from every plant was excised and the

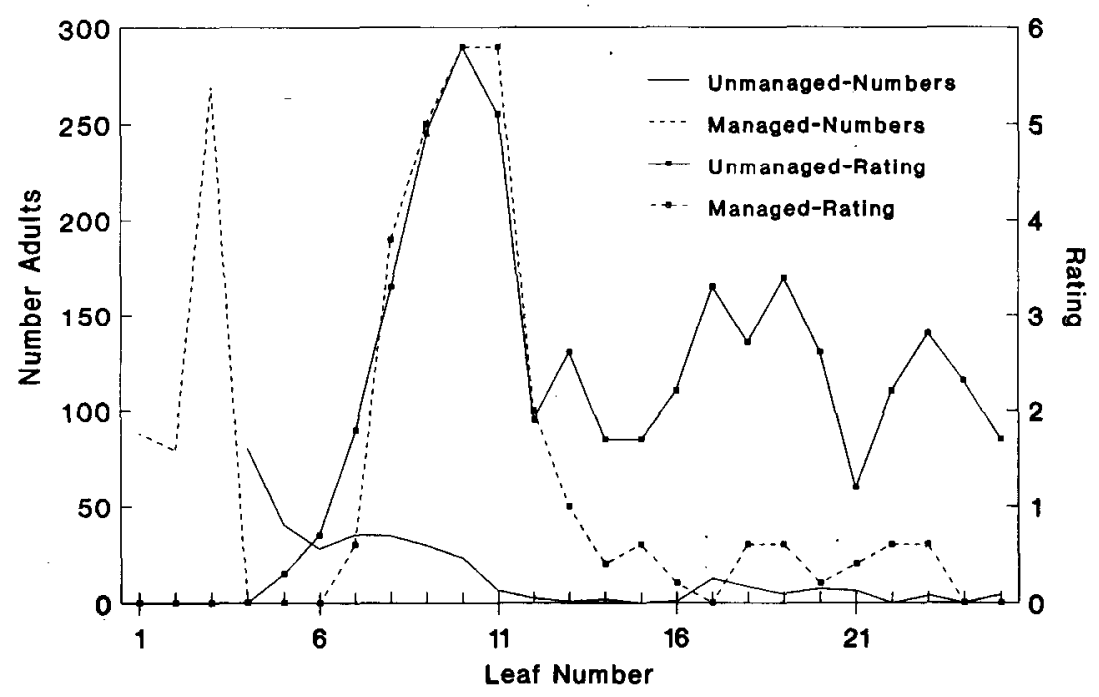

Fig. 1. Relationship between the number of sweetpotato whitefly immatures (eggs, crawlers, sessile nymphs, and pupae) and the combined ratings of 0 to 5 for increasing severity of expression of vein blanching and leaf silvering of acorn squash (combined rating is 0 to 10). Unmanaged plants were continuously infested for the duration of the experiment while managed plants had whitefly-infested leaves excised before being fumigated with insecticidal smoke and being treated with granular aldicarb. 


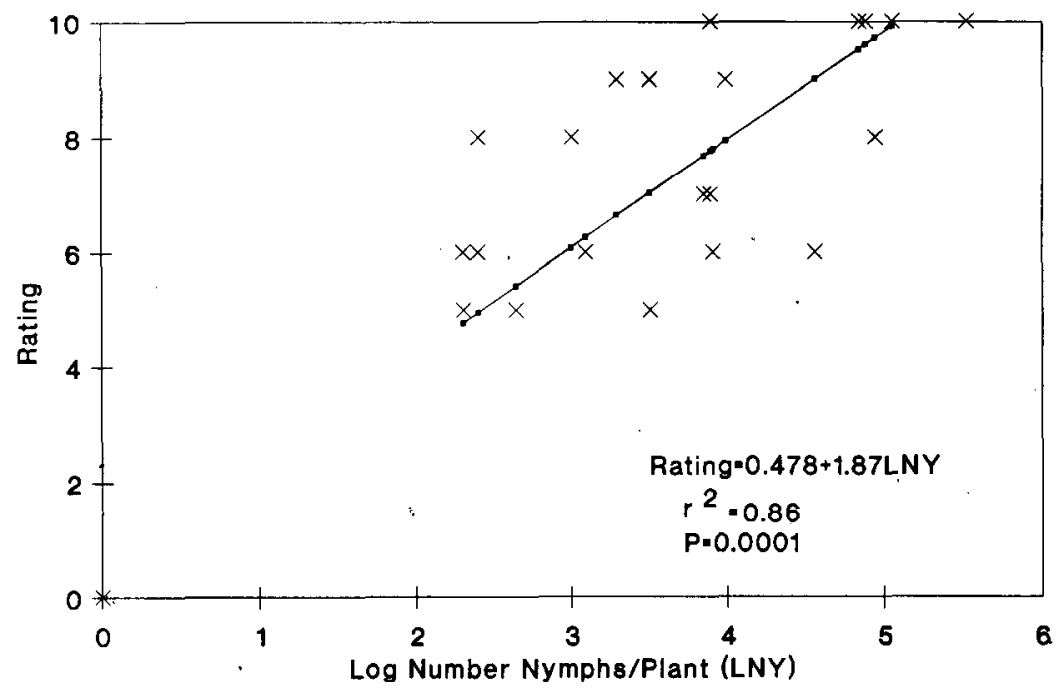

Fig. 2. Relationship between the log density of sweetpotato whitefly nymphs and combined ratings of 0 to 5 for increasing severity of expression of vein blanching and leaf silvering of acorn squash (combined rating is 0 to 10 ).

number of sweetpotato whitefly immatures was counted as above. Each leaf was rated 1 to 5 , separately for vein blanching and interveinal silvering, where $0=$ none, $1=$ trace, $2=$ trace to $\langle 25 \%, 3=25 \%$ to $49 \%$, $4=50 \%$ to $75 \%, 5=>75 \%$. The two forms of symptoms were rated independently since it appeared that initial leaf silvering did not always occur at the same severity as vein blanching. However, for summarization purposes, the separate ratings were combined for a total rating of $\mathrm{O}$ to 10 .

In the second experiment, 'Table Ace' acorn squash was seeded into three pots, as above, for each of 12 cages. On 22 June 1989, when each plant had one true leaf, plants were thinned to one per pot and fumigated with sulfotepp. On 23June, each leaf was enclosed in an organdy cloth sleeve cage. The sleeve cages on plants in nine of the larger cages were each infested with three pairs of the sweetpotato whitefly collected from a colony maintained in the greenhouse on squash plants exhibiting silverleaf symptoms. Three days later, the adults in the organdy cages. in six of the larger cages were removed and the number of eggs per leaf adjusted to either 20 or 150 by removing excess eggs with a dissecting needle. The adults in the sleeve cages on the plants in the remaining larger cages were not disturbed. On 5 to 6 July, each leaf of each plant was excised and the densities of whitefly nymphs and severity of silverleaf symptoms evaluated as in the first experiment. Log density was regressed against the combined ratings for blanching and silvering symptoms of the most severely affected leaf of each plant.

No symptoms of vein blanching or leaf silvering developed on uninfested squash plants in the first experiment. The first expression of vein blanching and silvering of leaves on infested plants appeared on leaves 5 to 6 (counting from the bottom) and peaked on leaves 10 to 11 (Fig. 1). None of these leaves were present at the time of the initial infestation. When the bottom three infested leaves were removed and further infestation excluded chemically, symptomatic leaves remained symptomatic and new leaves were asymptomatic or nearly so. Symptomatic leaves on these whitefly-managed plants were uninfested with whitefly immatures. New leaves on the continuously infested plants continued to develop symptoms, although at lower severity ratings, probably because infestations of immatures were lower on later leaves than on the first three leaves. This result could not be confirmed, however, since the lower three leaves on the continuously infested plants became necrotic before the end of the experiment and could not be evaluated for densities of whitefly immatures. Densities on these leaves were probably similar to densities on corresponding leaves on the whitefly-managed plants (counted midway through the experiment) since the severity and pattern of symptom expression on leaves six to 12 were similar.

As in the first experiment, no symptoms of silverleaf were manifested on uninfested plants in the second experiment. By varying the duration of adult exposure or the density of eggs, a range of whitefly nymphal densities from 0 to 250 per plant was established. When the log nymph density was regressed against the combined rating of vein blanching and leaf silvering of the most severely affected leaf, a significant linear relationship was observed (Fig. 2). This result suggests a secondary role of adults in the expression of silverleaf. If the adults were the primary means of incitation of symptoms, all infested plants should have exhibited similar severity of symptoms since all received the same number of adults.

The results of these experiments support the findings of earlier reports with other types of squash. Silverleaf symptoms were always associated with infestations of the sweetpotato whitefly. Symptoms were produced on leaves not present at the time-of infestation and were produced on leaves not infested with immatures. Symptomatic leaves remained symptomatic while new leaves produced after removal of the whitefly infestation were asymptomatic or nearly so. Symptom expression appeared to be related more to nymphal density than to adult density since the relationship between log nymph density and symptoms was linear even though adult densities were equal.

\section{Literature Cited}

Bharathan, N., W.R. Graves, K.R. Narayanan, D.J. Schuster, H.H. Bryan, and R.T. McMillan, Jr. 1990. Association of double stranded RNA with whitefly-mediated silvering in squash. Plant Pathol. 39:530-538.

Burger, Y., H.S. Paris, H. Nerson, Z. Karchi, and M. Edelstein. 1983. Overcoming the silvering disorder of Cucurbita. Cucurbit Genetics Coop. 6:70-71.

Hoelmer, K.A., L.S. Osborne, and R.K. Yokomi. 1991. Foliage disorders in Florida associated with feeding by sweetpotato whitefly, Bemisia tabaci. Fla. Entomol. (In press.)

Maynard, D.N. and D.J. Cantliffe. 1989. Squash silverleaf and tomato irregular ripening: new vegetable disorders in Florida. Fla. Coop. Ext. Ser., VC-37.

Paris; H.S., H. Nerson, and Y. Burger. 1987. Leaf silvering of Cucurbita. Can. J. Plant Sci. 67:593-598.

Schuster, D.J. and J.F. Price. 1987. The western flower thrips and the sweetpotato whitefly: New pests threatening Florida tomato production. Univ. of Fla., IFAS, Bradenton GCREC Res. Rpt. BRA1987-16.

Simons, J.N., P.J. Stoffella, K.D. Shuler, and R.N. Raid. 1988. Silver-leaf of squash in South Florida. Proc. Fla. State Hort. Soc. 101:397399.

Yokomi, R.K., L.S. Osborne, and K.A. Hoelmer. 1990. Relationship between the sweetpotato whitefly and the squash silverleaf. Phytopathology. 80:895-900. 